although the mechanism remains unclear. Other cases have also reported some improvement in symptoms following psychotherapy once the underlying cause of emotional stress has been identified.

\section{PO-0170 HEMOPHAGOCYTIC LYMPHOHISTIOCYTOSIS ASSOCIATED WITH VISCERAL LEISHMANIASIS: A CASE REPORT}

${ }^{1} \mathrm{~S}$ Ucar, ${ }^{2} \mathrm{P}$ Zorlu, ${ }^{3} \mathrm{NESE}$ Yarali, ${ }^{4} \mathrm{G}$ Tanir. ${ }^{1}$ Department of Pediatrics, OSM Middle East Hospital, Sanliurfa, Turkey; ${ }^{2}$ Department of Pediatrics, Dr. Sami Ulus Maternity and Children's Health and Diseases Training and Research Hospital, Ankara, Turkey; ${ }^{3}$ Department of Pediatric Hematology, Dr. Sami Ulus Maternity and Children's Health and Diseases Training and Research Hospital, Ankara, Turkey; ${ }^{4}$ Department of Pediatric Infection Diseases, Dr. Sami Ulus Maternity and Children's Health and Diseases Training and Research Hospital, Ankara, Turkey

\subsection{6/archdischild-2014-307384.833}

Background and aims Hemophagocytic lymphohistiocytosis $(\mathrm{HLH})$ is a rare, life threatening disorder characterizedby uncontrolled activation of T-helper 1 lymphocytes and macrophages and overproductionof inflammatory cytokines. Visceral leishmaniasis (VL), is a multisystem infection caused by the dissemination of Leishmania throughout the reticuloendothelial system. $\mathrm{HLH}$ associated VL is a rare and difficult to diagnose clinicopathological condition leading to delayed treatment. We report a rare case of HLH associated Visceral Leishmaniasis in a patient who presented with persistent high fever, hepatosplenomegaly and pancytopenia.

Case A 11 month-old baby with persistent high fever for more than 3 weeks and hepatosplenomegaly was assessed. Laboratory testing revealed pancytopenia, hypertriglyceridemia, hyperferritinemia and hypofibrinogenemia. Bone marrow examination revealed hemophagocytosis. A diagnosis of hemophagocytic syndrome was made according to the HLH-2009 diagnostic criteria. Prior to establishing the diagnosis of Leishmaniasis by indirect fluorescent antibody testing, several potential infectious agents were excluded. Treatment with pentavalent antimonials provided relief of all signs and symptoms within ten days.

Conclusion HLH should be included in the differential diagnosis of patients who present with persistent high fever, hepatosplenomegaly and pancytopenia. Besides, physicians should keep in mind Leishmaniasis among the potential etiologic factors of secondary HLH.

\section{P0-0171 FEATURES OF CLINICAL AND EPIDEMIOLOGICAL CHILDREN WITH SICKLE CELL ADMITTED IN TEACHING HOSPITAL ALCIDES CARNEIRO (HEAC), PETRÓPOLIS, RJ, BRAZIL}

E Veiga, A Veiga, A Ramos. Pediatria, Faculdade Medicina de Petrópolis, Petrópolis, Brazil

\subsection{6/archdischild-2014-307384.834}

Introduction According to the Ministry of Health, 3500 children are born each year with sickle cell disease in Brazil with $34.28 \%$ in Rio de Janeiro. Due to chronicity, complications and impact on the family and society, we choose to seek to know the evolving clinical features of sickle cell children seen in Petrópolis, Rio de Janeiro, Brazil.

Objective To describe the clinical and epidemiological characteristics of sickle cell anaemic children requiring hospitalisation in HEAC, Petrópolis, RJ, Brazil, in 2013.
Methodology Descriptive, retrospective, cross-sectional, quantitative study, documentary analysis of medical records of children hospitalised from January, 1 to December, 31, 2013, patients with sickle cell disease (SCD).

Results 11 patients were included and 12 hospitalizations. Diagnosis made by neonatal screening in 54.54\%. Males: $63.63 \%$. Mean age of 6.4 years $(12.4 \mathrm{y}-8 \mathrm{~m})$ Stay hospital ranged from 3 to 10 days (mean 6 days). All mentioned earlier hospitalizations. Nutritional assessment showed $81.8 \%$ of normal weight. Reasons for hospitalizations: $50 \%$ painful crises, pneumonia, $41.66 \%$ and $16.66 \%$ splenic sequestration. Need for blood transfusions in $50 \%$ of patients and $27.27 \%$ have splenectomized. Medical monitoring irregular in $36.47 \%$ patients.

Conclusion It is known that the prognosis of SCD is variable. Appropriate monitoring, workup appropriate therapeutic approach and the events should suit purposeful action strategies to reduce complications and also minimise the consequences resulting from the disease itself. Being the HEAC solely responsible for paediatric hospitalizations in the city, this study points to the implementation of protocols and control of action aimed at better prognosis of these children.

\section{P0-0172 BEHIND CLOSED DOORS: THE EFFECTS OF CHILDHOOD CANCER ON SOMATIC HEALTH OF PARENTS DURING AND AFTER ONCOLOGIC THERAPY}

${ }^{1} \mathrm{R}$ Wyrebek, ${ }^{1} \mathrm{G}$ Karpinsky, ${ }^{1} \mathrm{~B}$ Warszawski, ${ }^{1} \mathrm{P}$ Gorski, ${ }^{2} \mathrm{E}$ Bien, ${ }^{2} \mathrm{M}$ Krawczyk. ${ }^{1}$ English Division Pediatric Oncology Scientific Circle, Medical University of Gdansk, Gdansk, Poland; '2Department of Pediatrics Hematology and Oncology, Medical University of Gdansk, Gdansk, Poland

\subsection{6/archdischild-2014-307384.835}

Background Though surviving childhood cancer is a triumph for child and family, scars left on parents' health may linger long after treatment has been concluded.

Aim To analyse the impact of childhood cancer on somatic health of parents during treatment (DT: median 5.5 months) and after (AT: median 2 years).

Methods Analysis of 70 questionnaires (45 DT, 25 AT) from parents of cancer patients, treated at the Department of Paediatrics, Oncology and Haematology, Medical University of Gdansk, Poland, since 2011.

Results Over 60\% in both groups reported feeling physically worse since diagnosis and constantly worrying about their child. Parents DT had increased caffeine, nicotine and alcohol consumption, weight changes and hypertension. Two parents DT admitted to suicidal attempts, one developed cancer. Dermatological signs, mainly hair loss, were common both DT and AT. Both groups had sleeping difficulties; however, more AT experienced nightmares (20\% vs. $7 \%$ DT) and felt anxious and tired $(60 \%$ vs. $33 \%$ DT). Headaches, problems concentrating and migraines prevailed AT (60\%, 44\% and 28\% vs. 44\%, $29 \%$ and $7 \%$ DT; respectively). Cardiologic symptoms (tachycardia, dyspnea), gastrointestinal (gastroesophageal reflux, diarrhoea) and joint/bone pains predominated AT. $28 \%$ of parents AT felt unhappy with their intimate relationship (vs. 9\% DT). Only $20 \%$ of parents consulted with psychiatrist.

Conclusion Diagnosis of paediatric cancer leaves devastating somatic sequelae in parents, affecting all systems and life activities. Interestingly, parents AT report somatic complications more often than those DT. Medical assistance should be promoted for parents of cancer children even after termination of oncologic therapy. 